\title{
Joint Optimal Production Planning for Complex Supply Chains Constrained by Carbon Emission Abatement Policies
}

\author{
Longfei He, Zhaoguang $\mathrm{Xu}$, and Zhanwen Niu \\ College of Management and Economics, Tianjin University, Tianjin 300072, China \\ Correspondence should be addressed to Zhaoguang Xu; zhaoguangxu022@163.com
}

Received 4 April 2014; Accepted 2 June 2014; Published 16 July 2014

Academic Editor: Xiaolin Xu

Copyright ( 2014 Longfei He et al. This is an open access article distributed under the Creative Commons Attribution License, which permits unrestricted use, distribution, and reproduction in any medium, provided the original work is properly cited.

\begin{abstract}
We focus on the joint production planning of complex supply chains facing stochastic demands and being constrained by carbon emission reduction policies. We pick two typical carbon emission reduction policies to research how emission regulation influences the profit and carbon footprint of a typical supply chain. We use the input-output model to capture the interrelated demand link between an arbitrary pair of two nodes in scenarios without or with carbon emission constraints. We design optimization algorithm to obtain joint optimal production quantities combination for maximizing overall profit under regulatory policies, respectively. Furthermore, numerical studies by featuring exponentially distributed demand compare systemwide performances in various scenarios. We build the "carbon emission elasticity of profit (CEEP)" index as a metric to evaluate the impact of regulatory policies on both chainwide emissions and profit. Our results manifest that by facilitating the mandatory emission cap in proper installation within the network one can balance well effective emission reduction and associated acceptable profit loss. The outcome that CEEP index when implementing Carbon emission tax is elastic implies that the scale of profit loss is greater than that of emission reduction, which shows that this policy is less effective than mandatory cap from industry standpoint at least.
\end{abstract}

\section{Introduction}

People around the world have gradually realized that carbon dioxide emission has become a global environmental and energy issue as discussed in the World Climate Conference held in 2009 in Copenhagen [1]. To cut carbon emission into certain levels, governments in many countries put forward emission reduction targets confronting pressure both from internationally and domestically environmental concerns [2] . Therefore, governments have designed a series of carbon abatement policies to serve these carbon emission reduction purposes, say mandatory cap, carbon and trade, carbon tax, and carbon offset policies in the report of Congress of the United States [3]. Apparently, a variety of manufacturing industries as one of the main bodies emitting carbon dioxide are definitely subject to those emission reduction regulations.

On the way to confront the carbon emission regulations, firms over a great range of industries have to take a series of actions on reducing their own carbon emission. For firms' response to carbon emission regulations, we can observe from practice or reports that their common actions are often reflected in the replacement of energy-saving equipment, adoption of low-carbon technology for new product development, substitution of fossil fuels and saving in consumption of electricity power, and so forth [4]. For example, manufacturers can renew their old machine with high emission by turning to low-carbon emitted equipments.

Different from those aforementioned means for meeting carbon emission constraints, a few of companies are aware of the possibility in reducing emission by operations adjustment. This is an attractive and plausible solution in the lowcarbon economic environment. However, this kind of actions led only by single firm is not easy to achieve the anticipated goals. There are two reasons: a single firm is usually selfinterest oriented even when choosing her emission reduction operations strategies, which will be often distorted by the interactions with her supply chain partners; the other is the carbon footprint of final product which is accumulated through the whole supply chain process over installations one by one as well as the pipeline. However, the carbon footprint 
reflected in the carbon label will affect the market demand due to consumers' low-carbon awareness and in turn influence each firm's profit, eventually.

Although the government has released a couple of carbon emission regulatory policies for changing all carbon emitters' behaviors, especially for firms in industries, we should ask whether those policies can get their initial expected effect in carbon emission control. Upon the intuition, one can infer that some carbon emission regulation may not work well if it is originated from controlling single firm emission behavior but not from supply chain. The interactions among firms in the supply chain usually incur behaviors deviating from the goal of the whole system. In low carbon environment, firms in supply network also have different appeals when confronting various regulatory carbon emission policies. The low-carbon concerns will worsen the conflict of interests among node firms. This is the reason why we focus on supply chain production planning under carbon emission constraints in this study.

In this paper, our goal is to study the impact of various carbon emission regulations on the operations and then the performance of a complex supply chain network that is assembly system like made up of a series of nodes with convergent material flows to the final product. In this system, each node firm's production is constrained by her own emission regulatory policy, say either mandatory cap or carbon tax as we exploit afterwards. In contrast to single firm production planning problem under low-carbon scenario, we turn to focus on a more realistic and typical manufacturing system as we show here, which attracts us to investigate how we manage a set of manufacturing units under low-carbon era compared with traditional setting without low-carbon thinking. This kind of comparison can uncover the impact of carbon emission regulations on the typical supply chain network. Under systemic centralized setting, we formulate the problem as constrained nonlinear programming with $n$ dimensional variables.

On the other hand, we conduct another kind of comparison of performances resulted from two distinctive emission regulatory policies, respectively. We intend to measure and show the difference of two policies' transmission mechanisms through the whole supply network, which is designed to inspire our interest and thinking on the link of supply chain operations and public administrative policies. To achieve this target, we induce some metric index in terms of individual level and system level profits and emissions.

There are several streams of research related to our work. For an extensive survey in general on the operations management in low-carbon environment, see Benjaafar et al. [4] and Xia et al. [1]. Some researchers holding the macroperspective have studied the relationship between carbon emissions and the national economy; see Dhakal [5], Holtz-Eakin and Selden [6], and Zhang and Cheng [7] while many other studies consider the evaluation and influential factors of carbon emissions. Similarly, some researches pay attention to the relationship between macroeconomic factors and carbon emissions. Leng [8] develops a theoretical analysis of environmental economics for analyzing the impact of economic factors on carbon emissions. In this direction, further analysis on how economic factors affect carbon emissions was conducted by Zhu et al. [9] and Sun and Chen [10]. They also propose that the adjustment of the industrial structure, enhancement of energy efficiency, and transformation of the energy structure are among the emphases of energy conservation. Whereas being obviously different from the abovementioned literatures, our study focuses on microfirm and especially the network-level organization operations considering emission constraints.

Another relevant stream in this area focuses on the impact of policy instruments on the carbon emission reduction, and these instruments can be summarized as mandatory emission caps, taxes on emissions, cap-and-trade, and cap-and-offset; see Cropper and Oates [11], Hepburn [12], Webster et al. [13], and Bureau [14]. While these researches study the impact of public policies on the carbon emission reduction, they do not link operations management and public policy making for reducing carbon emission and also do not compare the effectiveness of carbon emission control under different policies.

Another relevant stream to our work are papers that consider the influence of carbon emissions policies on the industrial firms' production and inventory decisions, profits and costs, and so forth. Benjaafar et al. [4] and Benjaafar et al. [15] are among the first who proposed how to achieve the targeted emission reduction effect only from the perspective of manufacturing operations when a single firm was subject to carbon emissions regulations. Pan [16] investigates the carbon emission reduction and production planning of a single company as well as duopoly companies both under the carbon tax and cap-and-trade policies, respectively. But his study does not take the excess inventory generated emissions into account. As a contrast, Kang and Yoon [17] study the case considering the emissions incurred by inventory. For further exploring the relation between profit and emission reductions, Song and Leng [2] exploiting classic single-cycle newsvendor model investigate the optimal quantity ordering under three kinds of emission regulatory policies, that is, mandatory emission cap, emissions tax, and cap-and-trade. Afterwards, Chen et al. [18] research a similar problem, but they adopt the conventional EOQ model by assuming that the market demand rate is constant and shortage is not permitted. Although considering the comparison of performances incurred by different policies, the above researches are limited to a single firm and therefore do not study the impact of carbon emission regulations on supply chains. On the contrary, this is just the gap our work attempts to fill.

The most highly related research stream on low-carbon supply chain mainly focus on supply chain design and production system decisions. They argue that structure of the supply chain plays an important role in the chainwide carbon emissions, so it is important to optimize the supply chain design to achieve the emission control goal; see Cachon [19], Ramudhin et al. [20], and Abdallah et al. [21]. Ramudhin et al. [20] established a mixed integer programming model for a green supply chain redesign. On its basis, Ramudhin et al. [22] consider the life cycle assessment in the supply chain design. As a further study developed by Cachon [19], he considers the impact of two aspects supply chain structure and operations on carbon emissions. Another research direction 
on production decisions of supply chain under the lowcarbon policies is primarily derived by Benjaafar et al. [15]. They study how to optimize operations (such as procurement, production, and inventory controlling) in supply chain under emission regulations. Abdallah et al. [21] establish a mix integer programming (MIP) model to minimize carbon emissions. Similar to our study, Zhao and Lv [23] construct a model for some supply chain operations and develop optimal policy to minimize the chainwide overall carbon emissions. The supply chain structures considered in these literatures are relatively simple, and few studies above discuss the relation between system profit and carbon emission of the whole supply chain. Being compared with these literatures, the supply chain structure studied in this paper is more likely to reflect the reality of assembly-system-like supply chain, the characteristics of which lead to more sophisticated operations to handle under low-carbon oriented polies.

In this study, we concentrate on an assembly-system-like complex supply chain, as described in $\mathrm{He}$ [24], but with existence of various carbon emission regulations. We take both of production relevant and inventory-incurred carbon emission into account with the supply chain firm suffering random demands from the system outside. Combining the input-output technology, we establish a system production planning model of the supply chain and get the optimal production planning for each firm as well as the whole supply chain. What is more, we demonstrate the impact of the emissions reduction on the production decision-making. And we analyze how to adjust emissions reduction policy for public administration to reach the goal of carbon emissions reduction. Moreover, we introduce the concept of "carbon emissions elasticity of profit" index to evaluate the effect of emissions reduction policy.

The rest of the paper is organized as follows. We begin by addressing the problem this study focuses on and introduce notation and assumptions. In Section 3, we discuss the complex supply chain production planning in the setting without carbon emission regulations. The results here are to be compared with those in other scenarios. In Sections 4 and 5, we investigate the system planning problem considering typical carbon emission constraints of two low-carbon policies, namely, mandatory carbon emission cap and carbon emission tax, respectively. We present in these two sections how to make the optimal production planning by considering profit optimization and emission requirements simultaneously. In Section 6, we conduct numerical experiments and associated analysis to enrich and examine the solutions in afore sections. Section 7 comes by summarizing the managerial insights and possible extensions for research in the future.

\section{Notation, Assumptions, and Problem Formulation}

In this paper, we consider supply chains composed of a set of nodes firms, in which between a pair of nodes is the coupled demand according to physical structure of the final product. The integrator of the assembly supply chain makes product

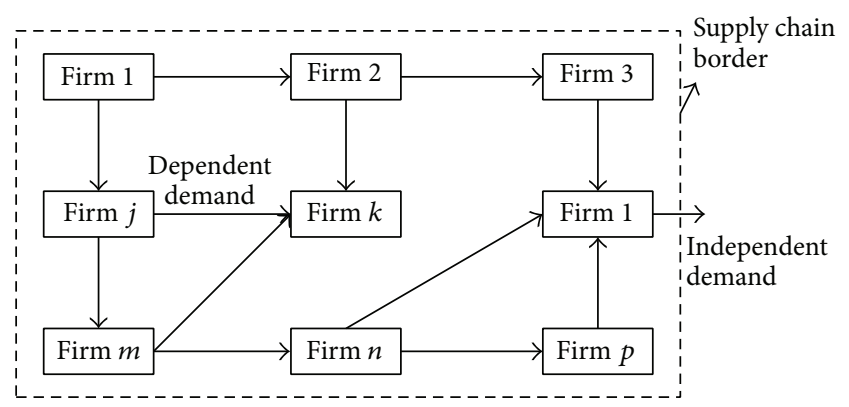

FIGURE 1: Schematic map of complex supply chain.

with multiprocess and a complex structure. For research simplicity without loss of generality, we assume that the product consists of a set of complementary component parts, each of which is uniquely produced by one node before the assembly. Demand relationship existing between a pair of nodes is determined by corresponding material flows, which are eventually installed by final product configuration. In other words, a node firm is the customer of her preceding node as well as the supplier of her succeeding node meanwhile.

There are two kinds of demands existing for each firm in the supply chain network, which are either from other node firms within or from organizations beyond the boundary of the network. Sorted by the source of the demand, the former is called dependent demand and the latter independent demand; see Jacobs and Chase [25]. There are quantity correlations between these two types of demands according to He et al. [26], which can be modeled by physical input-output analysis including the direct consumption coefficients and the total demand coefficients. The structure of the supply chain and its material flows are shown in Figure 1 as described in literature [27].

Embodied in the supply chain, there are three descriptions featuring the system operations: (1) to fabricate a final product, the production quantity for each company should meet a specific relationship which is determined by the configuration of the components in the final product; (2) each node firm should allocate her own capacity to satisfy relatively deterministic internal dependent demands and stochastic external demand simultaneously; (3) we assume the existence of an integrator as system controller to make a centralized decision by assigning productions distributed among all nodes to maximize total supply chain profit under carbon emission constraints. In this paper, we call above system related demand supply chain (RDSC) that is prevalent in the industry.

The complexity of managing the RDSC is mainly reflected in two aspects: (1) we should consider multinode synchronously to seek a global optimizer; pursuing the maximization of individual own interests, each node firm has his/her own interest appeal; this typical self-interested decentralized decision-making modes usually results in suboptimal performance both for its upstream and downstream companies, deviating from optimal decisions; (2) stochastic demands beyond and within the network boundary are intertwined with each other. The volatility of external random demand 
is passed through other nodes and then nodes are coupled together across the entire supply chain network, which raises the complexity of the production planning.

Moreover, driven by today's harsh climate change and challenging environmental issues, many countries have enacted a series of laws and regulations to limit carbon emissions. Two representative policies, the mandatory emission cap and carbon tax policies, are selected. Specific content of mandatory emission caps policy is that government requires carbon dioxide emissions of companies cannot exceed a given value within a given period. Carbon tax policy is to levy appropriate taxes according to the amount of carbon dioxide emitted during making business products or services, for the purpose of reducing carbon emissions.

In this paper, the related demand supply chain we researched faces the government's carbon reduction policy mentioned above. In this situation, the RDSC should adjust its production operational decisions. In the condition of mandatory emission caps policy, production of each company cannot be excessive; otherwise it will exceed the government's mandatory carbon emission limits; under carbon tax policy, if the company produces more, it will emit much more carbon emissions, resulting in more carbon taxes, but, on the other hand, company can sell more products and improve its revenue. So it is important to formulate appropriate production volume for the company in the supply chain to balance the relationship between carbon taxes and products revenue, in order to obtain maximum total profit of the supply chain.

We first figure out the optimal production decisions of node firms to maximize the supply chain profit in the condition without considering the carbon emission policy. And we give out analytical solutions of optimal production planning of dependent demand in complex supply chains. Then we consider how to adjust the production strategies of the company to maximize the chainwide profit in the condition of two kinds of carbon emissions policies as we mentioned. What is more, we investigate how to use these policies to achieve good effect of emission reduction while without substantial damages to the profit of the supply chain.

Parameters, Notation, and Assumptions. Parameters used in this paper are shown below.

\section{Parameters}

$N=\{1,2, \ldots, n\}:$ collection of all companies (products) in the supply chain

$X_{i}$ : stochastic market demand of independent demand product; its probability density function is $f_{i}\left(x_{i}^{L}\right)$, cumulative distribution function is $F_{i}\left(x_{i}^{L}\right)$, and mean value is $\mu_{i}$

$E_{i}$ : the actual carbon emissions of each company

$C_{i}$ : carbon emission quotas of each company

$K_{i}$ : fixed cost of each product

$v_{i}$ : variable cost of per unit of product

$h_{i}$ : inventory cost due to the presence of residual product $s_{i}$ : penalty cost due to shortage

$e_{i}^{m}$ : carbon dioxide emissions generated by the production of per unit of product

$E_{i}^{K}$ : fixed carbon emissions of each production

$e_{i}^{h}$ : carbon emissions of per unit remaining inventory

$p_{i}$ : unit price of each product

$\omega$ : carbon tax of per unit of carbon emissions.

\section{Decision Variables}

$q_{i}$ : stock after completion of the production of each company

$Q_{M}=\left[\ldots q_{i}^{M} \ldots\right]:$ production planning for dependent demand of each firm

$Q_{L}=\left[\ldots q_{i}^{L} \ldots\right]$ : production planning of independent demand for each firm

$Q_{S}=\left[\ldots q_{i}^{S} \ldots\right]$ : total production planning for each firm, $q_{i}^{S}=q_{i}^{L}+q_{i}^{M}$.

To make our research clear and simple without loss of generality and essence, we need to give out some assumptions as follows.

Assumption 1. Each node firm only produces one kind of component in supply chain.

Assumption 2. The initial inventory at each node firm is zero.

Assumption 3. Demand relationships between a pair of nodes in the supply chain are determined by the structure of the product and do not change over a single cycle.

Quantitative relationships between the inventory of companies upon completion of each production $Q$ and production planning of independent demand $Q_{L}$ can be connected by the direct consumption coefficient $a_{i j}$ and matrix $A=$ $\left\{a_{i j}\right\}_{n \times n}$. According to the input-output balanced equations, $\sum_{j=1}^{n} a_{i j} \cdot q_{j}+q_{i}^{L}=q_{i}$, so $Q=A \cdot Q+Q_{L}$. And we can get the following formula from the relationship between $Q$ and $Q_{L}$ :

$$
Q_{L}=(I-A) \cdot Q=B \cdot Q,
$$

where $B=I-A=\left\{b_{i j}\right\}_{n \times n}$.

We can prove that $(I-A)$ is a full-rank matrix and further calculate its inverse matrix. And another form of relationship between $Q$ and $Q_{L}$ can be rewritten as

$$
Q=(I-A)^{-1} Q_{L}=H \cdot Q_{L},
$$

where $D=(I-A)^{-1}=\left\{d_{i j}\right\}_{n \times n}$, and we call it absolutely necessary coefficient matrix. So it is obvious that the total production planning amount of each company can be derived from the production planning of independent demands, and the relationship between them is expressed as $q_{i}=$ $\sum_{j=1}^{n} d_{i j} q_{j}^{L}, i \in N$. Based on this relationship, we take the production planning of independent demands as the decision variable. 


\section{Production Planning Model of the Supply Chain without Carbon Emission Constraints}

In this section, we first consider production planning problem in the same complex supply chain system without emission constraints existing. The results in this setting are to be scaleplate compared with that in other scenarios. There exist two kinds of costs to be considered in this study. One is the inventory holding cost. The company produces more than the market demand and the remaining products needed to be stored. The parameter $h_{i}$ is the stock cost per unit of product. The other is the penalty cost. When the amount of the product cannot meet the demand of the market, the company should be punished with per unit product penalty cost $s_{i}$. We have assumed that there is no initial stock for each node firm. So the ending stock level $q_{i}$ is equal to the total production planning amount $q_{i}^{s}$ which is the sum of production planning of internal dependent demand and external independent demand; that is, $q_{i}=q_{i}^{s}=q_{i}^{L}+q_{i}^{M}$. And because supply and procurement within the supply chain is determined by the bill of materials (BOM) table, so the production planning of dependent demand of a company is determined by the total production planning amount of its downstream firms. Therefore, we can draw a conclusion that inventory costs and shortage costs are influenced by the relationship between production planning of independent demand and stochastic market demand.

We establish a vector $\Delta C\left(Q_{L}\right)=\left[\ldots, \Delta c_{i}, \ldots\right]$ considering inventory underage and overage simultaneously. We call it difference cost function between the production planning of internal demand and that of external demand, the expression of which is as follows:

$$
\Delta c_{i}=h_{i} \cdot\left(X_{i}-q_{i}^{L}\right)^{-}+s_{i} \cdot\left(X_{i}-q_{i}^{L}\right)^{+} .
$$

The practical significance of the formula above is that the differences' cost function contains the inventory costs and shortage costs. And it can be transformed into piecewise function in the following:

$$
\begin{aligned}
& \left(X_{i}-q_{i}^{L}\right)^{-}= \begin{cases}q_{i}^{L}-X_{i} & \text { where } X_{i}<q_{i}^{L} \\
0 & \text { where } X_{i} \geq q_{i}^{L},\end{cases} \\
& \left(X_{i}-q_{i}^{L}\right)^{+}= \begin{cases}0 & \text { where } X_{i}<q_{i}^{L} \\
X_{i}-q_{i}^{L} & \text { where } X_{i} \geq q_{i}^{L} .\end{cases}
\end{aligned}
$$

In addition to these two kinds of costs, we consider another two kinds of costs, that is, fixed cost and variable cost. Because we only consider the case of single-cycle, the fixed costs and variable costs per unit of product are constants, and variable costs are positively correlated with the total yields.

In this part, our target is to maximize the profit of the supply chain, and we construct the profit function according to the relationship that profit is equal to the value of revenue minus cost. The profit function is as follows:

$$
\begin{aligned}
\pi\left(Q_{L}\right)=\sum_{i=1}^{n}\left\{p_{i} \cdot \min \left(q_{i}^{L}, X_{i}\right)\right. \\
-\left[h_{i} \cdot\left(X_{i}-q_{i}^{L}\right)^{-}+s_{i} \cdot\left(X_{i}-q_{i}^{L}\right)^{+}\right. \\
\left.\left.+K_{i}+v_{i} \cdot \sum_{j=1}^{n} d_{i j} q_{j}^{L}\right]\right\} .
\end{aligned}
$$

On the right-hand side of the above equation, it is the profit of each firm that located in the curly braces. And the sum of individual company profit constitutes the supply chain profit. The first item in the curly braces is the revenue of the company and the company obtains it by selling the product to the market. We do not consider the revenue from selling product to the other companies inside the supply chain because this part of revenue is purchasing cost for them and this revenue and cost can be offset by the entire supply chain profit. And we can find that sales' volumes of each node firm are the minimum of the production planning of independent demand and the stochastic market demand. If the company produces more than the market demand, then the sales' volumes are determined by the planned production of independent demand. Otherwise the sales' volumes are equal to the market demand. The second part within the curly braces is the cost of the company which contains inventory costs, shortage costs, fixed costs, and variable costs.

If we know the probability density function and the cumulative distribution function of the stochastic market demand for node firm $i$, we can get the objective function to maximize the profit of the supply chain as follows:

$$
\begin{aligned}
\max \Pi=E(\pi)=\sum_{i=1}^{n}\{ & \left(p_{i}+s_{i}\right) \cdot q_{i}^{L} \\
& \quad-\left(p_{i}+h_{i}+s_{i}\right) \int_{0}^{q_{i}^{L}} F\left(X_{i}\right) d X_{i} \\
& \left.\quad-K_{i}-s_{i} \mu_{i}-v_{i} \cdot \sum_{j=1}^{n} d_{i j} q_{j}^{L}\right\}
\end{aligned}
$$

s.t. $\quad q_{i}^{L} \geq 0$.

It is obvious that the objective function is a second-order continuous function. If we want to get the optimal solution to maximize the profit, we should first prove that it is a concave function and then we calculate the first-order derivative of the function for the planned production of independent demand by equating it to zero. By solving the equations system we can obtain the optimal value of production planning. We prove 
the concavity of the function in the appendix. And the firstorder derivative of the function is as follows by letting it be zero:

$$
-p_{k}-s_{k}+\left(p_{k}+h_{k}+s_{k}\right) F_{k}\left(q_{k}^{L}\right)+\sum_{i=1}^{n} v_{i} d_{i k}=0
$$

From this equation, we can calculate the planning production of independent demand of each company. According to the relationship between planned production of independent demand and the total production of each company, we can calculate out some other kinds of production. And the expression of the planned production of independent demand is as follows:

$$
q_{k}^{L *}=F_{k}^{-}\left[\frac{p_{k}+s_{k}-\sum_{i=1}^{n} v_{i} d_{i k}}{\left(p_{k}+h_{k}+s_{k}\right)}\right] .
$$

It is obvious that there is no relation between the optimal planned productions of independent demand of a company with three parameters of other companies in the supply chain: the price, inventory holding cost, and shortage penalty cost per unit product. It is only influenced by these three cost factors of its own, but another finding is that optimal planning production of independent demand is related to the variable cost of per unit product of other companies in the supply chain. To learn more details of the research content as well as proofs shown in Section 3, please refer to literature [27]. And we will do a further study in the section of numerical analysis.

\section{Supply Chain Decision under the Mandatory Emission Cap Policy}

China's carbon emission occupies nearly $1 / 4$ of the world's emissions, which is the highest in the world. So China has been facing the pressure to cut emissions from the international community in the past. In contrast, China has said it would reduce its "carbon intensity" or the proportion of emissions relative to economic output. Related personnel of NDRC Energy Research Institute said that the NDRC was considering implementing an absolute upper limit of carbon emissions in the next five-year plan and now they were studying what is the appropriate level.

Mandatory emission cap policy is a good method to reduce carbon emissions, but the problem is that companies which are facing pressure from government must have flexibility on production decisions and also have an impact on corporate profits. This section is intended to study the impact of mandatory emission cap policy on the production decisions of supply chain members.

\subsection{Joint Optimization Model under Mandatory Emission Cap} Policy. In the case of mandatory emission cap policy, the company's total carbon emissions $E_{i}$ must not exceed government regulations value $C_{i}$.

At this time, the expected profit function is the same as the scenarios under no carbon emissions. Under the permit that each company satisfies $E_{i} \leq C_{i}$, objective function of the supply chain is

$$
\begin{aligned}
& \max _{q_{i}^{L}} \prod_{M C}\left(Q_{L}\right)=\sum_{i=1}^{n}\left\{\begin{array}{l}
\left(p_{i}+s_{i}\right) \cdot q_{i}^{L}-\left(p_{i}+h_{i}+s_{i}\right) \\
\cdot \int_{0}^{q_{i}^{L}} F_{i}(x) d x-s_{i} \mu_{i}-K_{i}
\end{array}\right. \\
& \text { s.t. } \left.E_{i} \leq v_{i} \cdot \sum_{j=1}^{n} d_{i j} q_{j}^{L}\right\} \\
& \quad q_{i}^{L} \geq 0 \\
& \forall i \in N,
\end{aligned}
$$

where $E_{i}=e_{i}^{m} \cdot \sum_{j=1}^{n} d_{i j} \cdot q_{j}^{L}+E_{i}^{K}+e_{i}^{h} \cdot \int_{0}^{q_{i}^{L}} F_{i}(x) d x$.

Company's total carbon emissions are equal to the sum of variable production relevant emissions, fixed production relevant emissions, and excess inventory relevant carbon emissions. Variable production relevant emissions are proportionally increasing in total number of products; that is, $e_{i}^{m} \sum_{j=1}^{n} d_{i j} \cdot q_{j}^{L}$; fixed production of emissions is $E_{i}^{K}$. The expected value of remaining inventory is $\int_{0}^{q_{i}^{L}} F_{i}(x) d x$, so the expected value of carbon emissions generated by the excess remaining inventory is $e_{i}^{h} \cdot \int_{0}^{q_{i}^{L}} F_{i}(x) d x$.

4.2. Interior Point Method to Solve the Problem. For general unconstrained optimization problem, there exists a variety of efficient algorithms currently. People usually transform the constrained problem into an associated unconstrained problem. Specifically, according to the constraint characteristics, they construct some kind of "punishment" function and then add it to the objective function; then the constraint solving problem is transformed into a series of unconstrained problem solving. In this respect, there are many algorithms, such as outside the penalty function method, the penalty function method, and the multiplier method.

As for the planning problem with inequality constraints under mandatory emission cap policy, this paper uses the penalty function method to solve it. In order to make iterative points always possible, the penalty function method builds a high "wall" on the boundary of the feasible region. When the iteration point is near the border, the objective function value suddenly increases, as a punishment to stop the iteration point across the border, and thus the optimal solution is blocked in the feasible region.

Before the use of penalty function method, we construct a penalty function and add it to the objective function. Specific steps are as follows. 
Step 1. Make the original problem into a minimization problem:

$$
\begin{aligned}
& \min J_{1}\left(Q_{L}\right)=\sum_{i=1}^{n}\left\{-\left(p_{i}+s_{i}\right) \cdot q_{i}^{L}+\left(p_{i}+h_{i}+s_{i}\right)\right. \\
& \cdot \int_{0}^{q_{i}^{L}} F_{i}(x) d x+s_{i} \mu_{i}+K_{i} \\
& \left.+v_{i} \cdot \sum_{j=1}^{n} d_{i j} q_{j}^{L}\right\} \\
& \text { s.t. } g_{i}\left(q_{i}^{L}\right)=C_{i}-e_{i}^{m} \sum_{j=1}^{n} d_{i j} \cdot q_{j}^{L} \\
& -E_{i}^{K}-e_{i}^{h} \cdot \int_{0}^{q_{i}^{L}} F_{i}(x) d x \geq 0 \\
& q_{i}^{L} \geq 0, \\
& \forall i \in N \text {. }
\end{aligned}
$$

Step 2. Structure a new planning with the form $\min _{Q_{L} \in \mathbb{R}^{n}} \varphi\left(Q_{L}\right.$, $\left.r^{(k)}\right)=J_{1}\left(Q_{L}\right)+r^{(k)} \sum_{i=1}^{n}\left(1 / g_{i}\left(Q_{L}\right)\right)$, where the penalty factor $r^{(k)}>0$.

Step 3. Given the initial point $Q_{L}{ }^{(0)} \in \mathbb{R}^{n}$, the allowable error $\varepsilon>0$, the penalty factor $\gamma^{(1)}>0$, and magnificence $b \in(0,1)$, set $k=1$.

Step 4. Take $Q_{L}{ }^{(k-1)}$ as the initial point; then solve the following planning problem: $\min _{Q_{L} \in \mathbb{R}^{n}} \varphi\left(Q_{L}, r^{(k)}\right)=J_{1}\left(Q_{L}\right)+$ $r^{(k)} \sum_{i=1}^{n}\left(1 / g_{i}\left(Q_{L}\right)\right) ; Q_{L}{ }^{(k)}$ is the minimal point.

Step 5. If $r^{(k)} \sum_{i=1}^{n}\left(1 / g_{i}\left(Q_{L}\right)\right)<\varepsilon$, stop calculating; the result is $Q_{L}{ }^{(k)}$.

Step 6. Otherwise $\gamma^{(k+1)}=b \gamma^{(k)}$, set $k=k+1$ and go back to step four.

\section{Supply Chain Decisions under Carbon Tax Policy}

Carbon tax originated in the British economist Pigou "Pigou's theory"; the theory is that in order to achieve effective control of pollution and pollutant emissions purposes, the government imposes tax on polluters according to the degree of harm caused. In order to achieve the reduction of carbon dioxide emissions and fossil fuel consumption, the government levies carbon tax on coal, gasoline, natural gas, jet fuel, and other fossil fuel products, according to the proportion of their carbon content. Carbon tax can take many forms and the simplest case is penalty with the linear growth of unit carbon emissions.

In this part, we study the impact of carbon tax policy on supply chain operations. In order to obtain the optimal supply chain profit, it is important to balance the relationship between the revenue and the tax brought by the production of the company. If the companies can sell more products and the revenue may cover the carbon emissions tax, it is clear that companies will choose to produce more. Conversely, companies produce less. We build the profit model of the supply chain under carbon tax policy in this part to study the impact of tax policy on production decisions in the complex supply chain.

Company $i$ needs to pay taxes $\omega$ for releasing per unit of carbon emissions. Companies' carbon emissions are $e_{i}^{m} \sum_{j=1}^{n} d_{i j} \cdot q_{j}^{L}+E_{i}^{K}+e_{i}^{h} \cdot\left(X_{i}-q_{i}^{L}\right)^{-}$, so companies need to pay taxes $\omega \cdot\left[e_{i}^{m} \sum_{j=1}^{n} d_{i j} \cdot q_{j}^{L}+E_{i}^{K}+e_{i}^{h} \cdot\left(X_{i}-q_{i}^{L}\right)^{-}\right]$. The carbon tax is a kind of cost in the profit function according to the profit function of no carbon emissions circumstances and the profit function can be expressed as

$$
\begin{gathered}
\prod_{\mathrm{CT}}\left(Q_{L}\right)=\sum_{i=1}^{n}\left\{p_{i} \cdot \min \left(q_{i}^{L}, X_{i}\right)-h_{i} \cdot\left(X_{i}-q_{i}^{L}\right)^{-}-s_{i}\right. \\
\cdot\left(X_{i}-q_{i}^{L}\right)^{+}-K_{i}-v_{i} \cdot \sum_{j=1}^{n} d_{i j} q_{j}^{L}-\omega \\
\cdot\left[e_{i}^{m} \sum_{j=1}^{n} d_{i j} \cdot q_{j}^{L}+E_{i}^{K}\right. \\
\left.\left.+e_{i}^{h} \cdot\left(X_{i}-q_{i}^{L}\right)^{-}\right]\right\} .
\end{gathered}
$$

So the model of maximizing expected profit of entire supply chain can be written as follows:

$$
\begin{gathered}
\max E\left(\prod_{\text {CT }}\right)=\sum_{i=1}^{n}\left\{\left(p_{i}+s_{i}\right) \cdot q_{i}^{L}-\left(p_{i}+h_{i}+s_{i}+\omega e_{i}^{h}\right)\right. \\
\cdot \int_{0}^{q_{i}^{L}} F_{i}(x) d x-\left(v_{i}+\omega e_{i}^{m}\right) \\
\left.\cdot \sum_{j=1}^{n} d_{i j} q_{j}^{L}-\omega E_{i}^{K}-s_{i} \mu_{i}-K_{i}\right\}
\end{gathered}
$$

s.t. $q_{i}^{L} \geq 0$

$\forall i \in N$.

First, we assume the profits function $\prod_{\mathrm{CT}}$ is second-order continuous. The presence of optimal solution for the above equation is that the first derivative of $\prod_{\mathrm{CT}}$ for a variety of independent demand $q_{k}^{L}(k \in N)$ is zero, and $\prod_{\text {CT }}$ is a concave function.

According to the method of proving $\prod$ to be a concave function, it is easy to prove that the profit function $\prod_{\mathrm{CT}}$ is also concave function. 
Then we seek first-order partial derivative of $\prod_{\text {СT }}$ for $q_{k}^{L}$ (for all $k \in N$ ) and set it to zero as follows:

$$
\begin{gathered}
-p_{k}-s_{k}+\left(p_{k}+h_{k}+s_{k}+\omega e_{k}^{h}\right) F_{k}\left(q_{k}^{L}\right) \\
+\sum_{i=1}^{n} d_{i k}\left(v_{i}+\omega e_{i}^{m}\right)=0 .
\end{gathered}
$$

So, we can get the optimal production planning of independent demand:

$$
q_{k}^{L *}=F_{k}^{-1}\left[\frac{p_{k}+s_{k}-\sum_{i=1}^{n} d_{i k}\left(v_{i}+\omega e_{i}^{m}\right)}{\left(p_{k}+h_{k}+s_{k}+\omega e_{k}^{h}\right)}\right] .
$$

\section{Numerical Experiments and Analysis}

In this section, we conduct numerical experiments to examine some conclusions or findings in preceding sections. A complex supply chain of one functional product is designed as in Figure 2.

Among these products, product $\mathrm{A}$ is the final product assembled which only faces random independent demand from external market while the products $\mathrm{B}, \mathrm{C}$, and $\mathrm{D}$ are all component parts and they are confronted with dependent demand from network nodes and independent demand of external market. According to the demand structure, we can get the direct consumption coefficient matrix $\mathrm{A}=[0,0,0,0$; $2,0,0,0 ; 1,1,0,0 ; 1,3,1,0]$.

Now, independent demand $x_{i}^{L}$ is assumed to subject to exponential distribution with parameter $\lambda_{i}$ and its mean value $\mu_{i}$, the probability density function $f_{i}\left(x_{i}^{L}\right)=\lambda_{i} e^{-\lambda_{i} x_{i}^{L}}$, and the cumulative distribution function is $F_{i}\left(x_{i}^{L}\right)=1-e^{-\lambda_{i} x_{i}^{L}}$.

In seek of further analysis of joint optimization strategy of production for the supply chain, we set up several groups of experiments in this paper through numerical simulation to study the relationship between decision variables and some key parameters under the carbon emissions policy.

6.1. Analysis of Planned Production of Each Company under No Carbon Emissions Constraints. The optimal planned production of independent demand of each company is

$$
q_{k}^{L *}=-\mu_{k} \ln \left[1-\frac{p_{k}+s_{k}-\sum_{i=1}^{n} v_{i} d_{i k}}{\left(p_{k}+h_{k}+s_{k}\right)}\right] .
$$

As we can see from the formula, the optimal planned production of independent demand of each company only has the correlation with factors of its own including the product market demand, product prices, the inventory cost, penalty cost, and the initial inventory and is not affected by these factors of other companies. According to the absolutely necessary coefficient matrix, we get $d_{i k}=0$, where $k>i$. It means that when company $i$ is a customer to company $k$ we get $d_{i k}=$ 0 . At this time, companies' optimal planned production of independent demand will not be influenced by their customers' variable cost per unit of product. And we can get $d_{i k}>$ 0 , where $k<i$. It means that when company $i$ is a supplier of

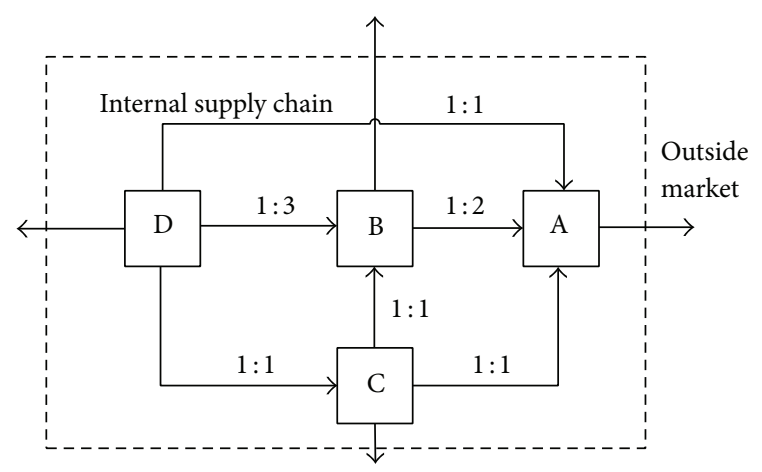

FIGURE 2: A manufacturing supply chain structure.

company $k$ we get $d_{i k}>0$. Thus, to customers, their optimal planned production of independent demand is influenced by variable cost per unit of product of their suppliers. Besides, planned production of independent demand of customer companies is on the decrease with the increasing of the suppliers' variable cost per unit of product. This phenomenon illustrates the importance of real powerful impact factorvariable cost per unit of product in the supply chain.

(1) This section mainly analyzes optimal planned production of independent demand trends under the given $\mu, P, H, S$, and the changes in production costs, thereby getting analysis of the influence of production cost vector on the system performance. Without loss of generality, we set $\mu=[100,112,120,140]^{T}, P=[10,6,4,1]^{T}, H=$ $\left[h_{1}, h_{2}, h_{3}, h_{4}\right]=[0.6,0.4,0.3,0.05]^{T}$, and $S=\left[s_{1}, s_{2}, s_{3}, s_{4}\right]=$ $[0.8,0.4,0.2,0.1]^{T}$. The production planning of independent demand and system profits are shown in Table 1.

From Table 1, it is not difficult to find that when the assembly plant A's production cost increases, its production planning amount related to independent demand decreases and that of its suppliers B, C, and D is unchanged. At this point the system gross profit is decreasing. When the factory B's production costs increases, planned production of independent demand of the factories $A$ and $B$ decreases, while that of $C$ and $D$ remains unchanged, and the total profits of the system decrease. When production cost of A, B and suppliers $C$ increases, the planned production of independent demand of $\mathrm{A}, \mathrm{B}$, and $\mathrm{C}$ was decreased, but that of raw materials supplier D is unchanged. And we can find that the total profit of the system has also gradually reduced in this case. It is an interesting insight that when the production costs of raw material supplier D increased, the planned production of independent demand of all the companies in the supply chain has reduced, and the total profit system has also gradually reduced. From the above analysis, we can find that the total profit of the system is negatively correlated to the production costs of each company. The planned production of independent demand of downstream company in the supply chain is affected by production costs of its own and its upstream suppliers, and there is a negative correlation between the planned production of independent demand and the production costs. But the planned production of independent demand of the upstream companies in the supply chain is only affected by its own production costs. 
TABLE 1: Production planning and system profits sensitivity analysis to $V^{p}$.

\begin{tabular}{lcc}
\hline$V^{p}$ & $\begin{array}{c}\text { Planned production of independent } \\
\text { demand }\end{array}$ & $\begin{array}{c}\text { System } \\
\text { profit }\end{array}$ \\
\hline$[0.6,0.4,0.4,0.08]$ & {$[104.73,167.80,210.30,305.20]$} & 803.06 \\
{$[0.8,0.4,0.4,0.08]$} & {$[99.85,167.80,210.30,305.20]$} & 782.61 \\
{$[1.0,0.4,0.4,0.08]$} & {$[95.20,167.80,210.30,305.20]$} & 763.11 \\
{$[1.2,0.4,0.4,0.08]$} & {$[90.76,167.80,210.30,305.20]$} & 744.51 \\
{$[1.4,0.4,0.4,0.08]$} & {$[86.50,167.80,210.30,305.20]$} & 726.79 \\
{$[1.6,0.4,0.4,0.08]$} & {$[82.42,167.80,210.30,305.20]$} & 709.90 \\
\hline$[1.6,0.6,0.4,0.08]$ & {$[74.72,153.96,210.30,305.20]$} & 646.35 \\
{$[1.6,0.8,0.4,0.08]$} & {$[67.58,141.63,210.30,305.20]$} & 588.37 \\
{$[1.6,1.0,0.4,0.08]$} & {$[60.91,130.54,210.30,305.20]$} & 535.49 \\
{$[1.6,1.2,0.4,0.08]$} & {$[54.65,120.44,210.30,305.20]$} & 487.31 \\
{$[1.6,1.4,0.4,0.08]$} & {$[48.77,111.18,210.30,305.20]$} & 443.49 \\
\hline$[1.6,0.4,0.4,0.08]$ & {$[82.42,167.80,210.30,305.20]$} & 709.90 \\
{$[1.6,0.4,0.6,0.08]$} & {$[71.08,153.96,182.91,305.20]$} & 592.55 \\
{$[1.6,0.4,0.8,0.08]$} & {$[60.91,141.63,160.63,305.20]$} & 489.19 \\
{$[1.6,0.4,1.0,0.08]$} & {$[51.67,130.54,141.84,305.20]$} & 398.06 \\
{$[1.6,0.4,1.2,0.08]$} & {$[43.21,120.44,125.60,305.20]$} & 317.84 \\
{$[1.6,0.4,1.4,0.08]$} & {$[35.42,111.18,111.30,305.20]$} & 247.47 \\
\hline$[1.6,0.4,0.4,0.08]$ & {$[82.42,167.80,210.30,305.20]$} & 709.90 \\
{$[1.6,0.4,0.4,0.10]$} & {$[78.50,162.05,207.27,285.16]$} & 670.55 \\
{$[1.6,0.4,0.4,0.12]$} & {$[74.72,156.59,204.30,267.64]$} & 632.84 \\
{$[1.6,0.4,0.4,0.14]$} & {$[71.08,151.38,201.41,252.07]$} & 596.70 \\
{$[1.6,0.4,0.4,0.16]$} & {$[67.58,146.40,198.59,238.06]$} & 562.03 \\
{$[1.6,0.4,0.4,0.18]$} & {$[64.19,141.63,195.83,225.32]$} & 528.76 \\
{$[1.6,0.4,0.4,0.20]$} & {$[60.91,137.06,193.13,213.65]$} & 496.82 \\
{$[1.6,0.4,0.4,0.22]$} & {$[57.73,132.67,190.50,202.87]$} & 466.17 \\
\hline & & \\
\hline 1.04
\end{tabular}

(2) This section mainly analyzes rends of planned production of independent demand $Q^{L}$ in a given $\mu, V^{p}, H$, and $S$ with the changes of product prices. Thereby we analyze the impact of the product price vector on system performance. Without loss of generality, we order $\mu=[100,112$, $120,140]^{T}, v=[1.6,0.4,0.4,0.08], H=\left[h_{1}, h_{2}, h_{3}, h_{4}\right]=$ $[0.6,0.4,0.3,0.05]^{T}, S=\left[s_{1}, s_{2}, s_{3}, s_{4}\right]=[0.8,0.4,0.2,0.1]^{T}$, and $K=[30,21,16,10]^{T}$. Planned production of independent demand and system profits is shown in Table 2.

It can be found in Table 2 that product price changes of each company will only affect the production planning of independent demand but will not affect other companies. With prices gradually decreasing, the production planning for external random demand is to decline. This indicates that the supply chain production operations decision is influenced by product prices vector. Similarly, the total profit of supply chain also goes down with decreasing prices.

6.2. The Analysis of Supply Chain Profits and Carbon Emissions under Mandatory Emission Caps Policy. This part is mainly devoted to the changing regularity of the total profit and the total carbon emission of the supply chain with the change of
TABLE 2: Planned production of independent demand and system profit sensitivity analysis to price $P$.

\begin{tabular}{lcc}
\hline Price $P$ & $\begin{array}{c}\text { Planned production of } \\
\text { independent demand }\end{array}$ & $\begin{array}{c}\text { System } \\
\text { profit }\end{array}$ \\
\hline$[10.0,6,4,1]$ & {$[82.42,167.80,210.30,305.20]$} & 709.90 \\
{$[9.5,6,4,1]$} & {$[77.93,167.80,210.30,305.20]$} & 682.33 \\
{$[9.0,6,4,1]$} & {$[73.24,167.80,210.30,305.20]$} & 655.81 \\
{$[8.5,6,4,1]$} & {$[68.31,167.80,210.30,305.20]$} & 630.44 \\
{$[8.0,6,4,1]$} & {$[63.13,167.80,210.30,305.20]$} & 606.36 \\
{$[7.5,6,4,1]$} & {$[57.66,167.80,210.30,305.20]$} & 583.68 \\
{$[7.0,6,4,1]$} & {$[51.88,167.80,210.30,305.20]$} & 562.59 \\
{$[6.5,6,4,1]$} & {$[45.74,167.80,210.30,305.20]$} & 543.28 \\
\hline$[10,6.0,4,1]$ & {$[82.42,167.80,210.30,305.20]$} & 709.90 \\
{$[10,5.5,4,1]$} & {$[82.42,159.25,210.30,305.20]$} & 666.91 \\
{$[10,5.0,4,1]$} & {$[82.42,149.98,210.30,305.20]$} & 624.98 \\
{$[10,4.5,4,1]$} & {$[82.42,139.89,210.30,305.20]$} & 584.33 \\
{$[10,4.0,4,1]$} & {$[82.42,128.79,210.30,305.20]$} & 545.20 \\
{$[10,3.5,4,1]$} & {$[82.42,116.47,210.30,305.20]$} & 507.93 \\
{$[10,3.0,4,1]$} & {$[82.42,102.62,210.30,305.20]$} & 472.97 \\
{$[10,2.5,4,1]$} & {$[82.42,86.82,210.30,305.20]$} & 440.99 \\
\hline$[10,6,4.0,1]$ & {$[82.42,167.80,210.30,305.20]$} & 709.90 \\
{$[10,6,3.8,1]$} & {$[82.42,167.80,204.85,305.20]$} & 690.16 \\
{$[10,6,3.6,1]$} & {$[82.42,167.80,199.13,305.20]$} & 670.62 \\
{$[10,6,3.4,1]$} & {$[82.42,167.80,193.13,305.20]$} & 651.30 \\
{$[10,6,3.2,1]$} & {$[82.42,167.80,186.82,305.20]$} & 632.23 \\
{$[10,6,3.0,1]$} & {$[82.42,167.80,180.15,305.20]$} & 613.43 \\
{$[10,6,2.8,1]$} & {$[82.42,167.80,173.09,305.20]$} & 594.93 \\
{$[10,6,2.6,1]$} & {$[82.42,167.80,165.58,305.20]$} & 576.79 \\
\hline$[10,6,4,2.0]$ & {$[82.42,167.80,210.30,392.80]$} & 838.52 \\
{$[10,6,4,1.8]$} & {$[82.42,167.80,210.30,379.13]$} & 812.29 \\
{$[10,6,4,1.6]$} & {$[82.42,167.80,210.30,363.98]$} & 786.26 \\
{$[10,6,4,1.4]$} & {$[82.42,167.80,210.30,346.99]$} & 760.47 \\
{$[10,6,4,1.2]$} & {$[82.42,167.80,210.30,327.65]$} & 734.99 \\
\hline & {$[82.42,167.80,210.30,305.20]$} & 709.90 \\
{$[82.42,167.80,210.30,278.45]$} & 685.38 \\
\hline $82.42,167.80,210.30,245.36]$ & 661.68 \\
\hline & & \\
{$[10,6]$} & & \\
& &
\end{tabular}

carbon caps $C$ under the given $\mu, P, H, S, X$, and $V^{p}$. Now, we give the value of these factors as follows:

$$
\begin{gathered}
P=[10,6,4,1]^{T}, \quad \mu=[100,112,120,140]^{T}, \\
H=[0.6,0.4,0.3,0.05]^{T}, \quad S=[0.8,0.4,0.2,0.1]^{T}, \\
K=[30,21,16,10]^{T}, \quad v=[1.6,0.4,0.4,0.08]^{T}, \\
e^{m}=[2,3,5,8]^{T}, \quad E^{K}=[20,14,12,10]^{T}, \\
e^{h}=[0.5,0.4,0.3,0.1]^{T} .
\end{gathered}
$$

We have gotten the optimal planning production of independent demand of each company under the condition of no carbon policy. Because of the existence of carbon discharge 
during the process of production or stock in the supply chain, we can calculate each company's carbon discharge, the total profit carbon emission of the supply chain system. We call all these values "datum carbon emissions," "datum system profit," and "datum total carbon emissions." This part majorly analyzed how the government should formulate the emission cap of each company when they develop the plans of reduction. Generally when the government develops a specific reduction policy, they will consult annual carbon emission data which we have mentioned above, that is, "baseline carbon emissions." We analyzed a case where the emission cap of each company, based on "baseline carbon emissions," reduces a number of percentage points respectively (one company reduced emission cap while others' is constant). This is equivalent to the government stepped up restrictions on carbon emissions for each company. It will inevitably lead to two consequences. First is that the profit of system will be affected; the second is that the system's total carbon emissions will be changed. And we obtain the change trends of system profit and carbon emission with the emission cap of each company reducing from 1 percent to 80 percent, respectively. The results are shown in Figures 3 and 4 .

As can be seen from Figure 3, it is obvious that, for each company, when the government tighten carbon emission cap, the total profit of the supply chain system is reduced. And the reduction volume is different when the government's tightening measures are applied in different company. And it is obvious that when the government strengthens restriction of the carbon emissions of company A, which is the assembly companies of the supply chain, system profit is reduced less than the case that the emission caps of other companies reduce the same percentage. From this perspective, it is better for supply chain when the government tighten carbon emission cap of company A. But from the perspective of the government, it would not be the best decision because government also needs to take the pressure of reduce emissions into account. For further study, we use Figure 4 to explore the changes of the system carbon emissions when the emission cap of each company is reduced by percentage.

We can find a remarkable phenomenon from Figure 4; when the emission cap of company A is reduced by a certain percentage from the "datum carbon emissions" (the emission cap of other companies are unchanged at this time), the supply chain carbon emissions is higher than the case that the emission cap of other company is reduced by the same proportion. From the government perspective, it could not be a perfect consequence. The government hopes that emissions reduction volume reduces more the better. So we can draw a conclusion that when the government can only tighten the emission cap of one company, it will tighten the emission cap of company $\mathrm{D}$ by a certain proportion to achieve a higher emission reduction effect, compared with the same reduction percentage of emission caps of other companies. It was totally opposed to the results of Figure 3, in which the supply chain wants the tightening policy to be applied on company A. So the effect of the carbon reduction with tightening emission cap of a company in the supply chain is ambivalent from the perspective of the government and supply chain. We try to introduce a kind of evaluation index to balance the

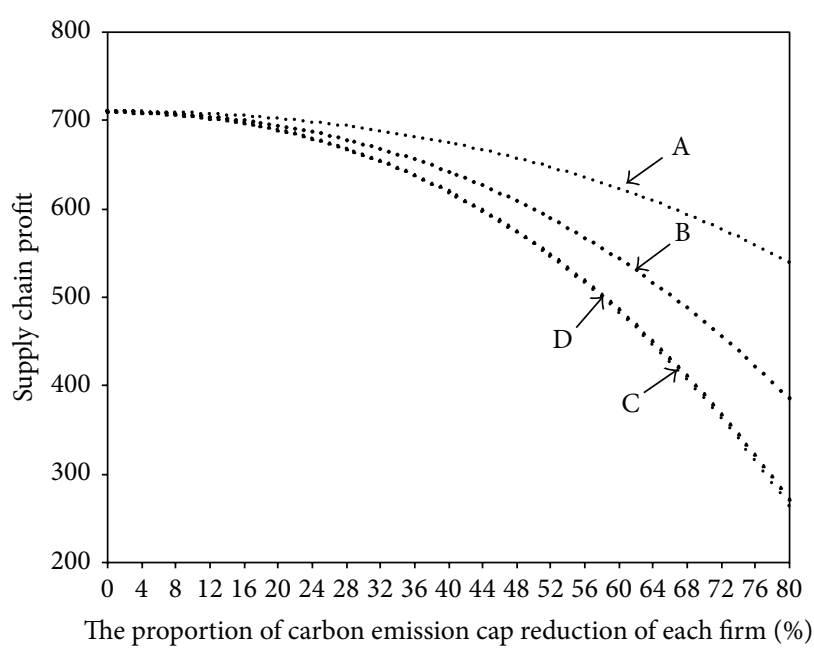

FIGURE 3: System profit when each company reduces carbon emissions by $1 \%-80 \%$.

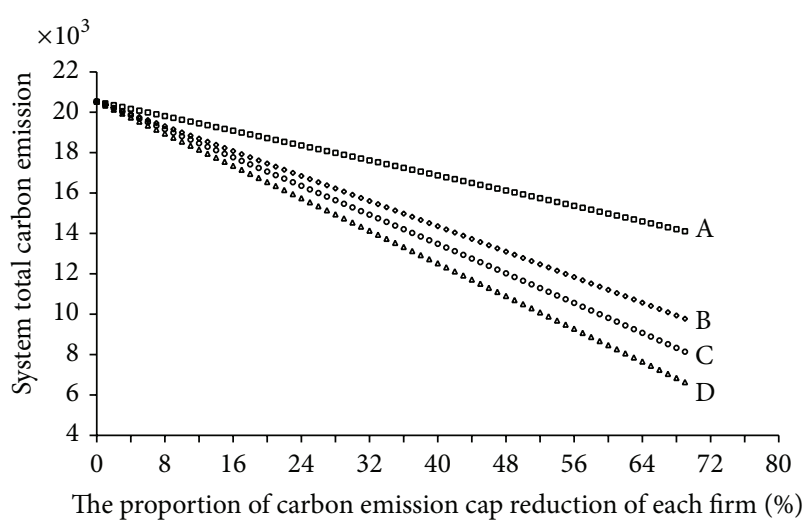

FIgURE 4: System emissions when each company reduces carbon emissions by $1 \%-80 \%$.

contradiction between the government and the supply chain. We define the indicators for "carbon emission elasticity of profit." Similar to the price elasticity of demand, the value of carbon emission elasticity of profit is the quotient from dividing change rate of system profits relative to the datum supply chain profit by change rate of supply chain carbon emission relative to datum total carbon emissions. If the value is between 0 and 1 , it means that the change rate of supply chain profit is less than the change rate of supply chain carbon emission. In this condition, the government will be very satisfied with the high proportion of carbon emissions reduction, and the supply chain is also happy that its profit is not reduced by a high proportion. Therefore, it is a very good result that the value of carbon emission elasticity of profit is between 0 and 1 . In addition, the carbon emission elasticity of profit is different when the government tightens the emission cap on different companies. Figure 5 analyzes the change of carbon emission elasticity of profit with the respectively reduction of emission cap of each company by a certain proportion.

As can be seen from Figure 5, carbon emission elasticity of profit is all between 0 and 1 with respective reduction of 


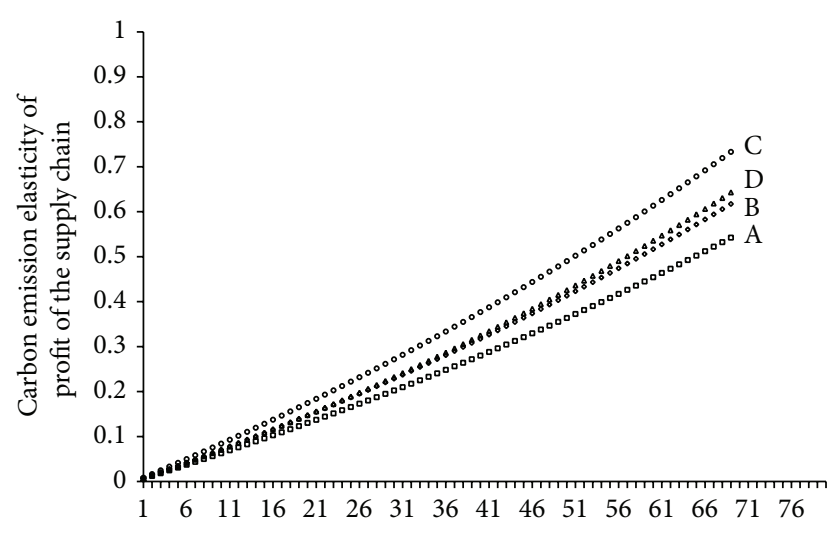

The proportion of carbon emission cap reduction of each firm (\%)

FIGURE 5: Carbon emission elasticity of profit with the respective reduction of emission cap of each company by a certain proportion.

emission cap of each company by a certain proportion, and the value increases with the increase of the reduction proportion. What is more, we can find that for A company, when its emission cap reduces a certain proportion, the carbon emission elasticity of profit is lower compared with the situation that other companies' emission cap reduce the same percentage. For example, when the reduction proportion of emission cap of company $\mathrm{A}$ is $2 \%$, the carbon emission elasticity of profit is 0.012 . At this time, the carbon emission elasticity of profit is lowest compared with the situation that other companies' emission cap reduce $2 \%$. In other words, in this situation, if the change rate of carbon emissions was $1 \%$, then the change rate of supply chain profit is only 0.012 . The effect is very significant for supply chain and the government. So both sides will be more inclined to reduce a certain proportion of emission cap of company A.

6.3. The Analysis of Supply Chain Profits and Carbon Emissions under Carbon Tax Policy. At this point all companies' optimal planned production of independent demand:

$$
q_{k}^{L *}=-\mu_{k} \ln \left[1-\frac{p_{k}+s_{k}-\sum_{i=1}^{n} d_{i k}\left(v_{i}+\omega e_{i}^{m}\right)}{\left(p_{k}+h_{k}+s_{k}+\omega e_{k}^{h}\right)}\right]-x_{k}^{0} .
$$

This part mainly analyzes trends of the optimal planned production of independent demand $Q$, total profit, and actual carbon emissions of supply chain with changes in the carbon tax $\omega$ per unit of carbon emissions under the given $\mu, P, H, S$, $v, e^{m}, E^{K}$, and $e^{h}$. The values of these factors are as follows:

$$
\begin{gathered}
\mu=[100,112,120,140]^{T}, \quad P=[10,6,4,1]^{T}, \\
H=[0.6,0.4,0.3,0.05]^{T}, \quad S=[0.8,0.4,0.2,0.1]^{T}, \\
K=[30,21,16,10]^{T}, \quad v=[1.6,0.4,0.4,0.08]^{T}, \\
e^{m}=[2,3,5,8]^{T}, \quad E^{K}=[20,14,12,10]^{T}, \\
e^{h}=[0.5,0.4,0.3,0.1]^{T} .
\end{gathered}
$$

\begin{tabular}{|c|c|c|c|}
\hline$\omega$ & $\begin{array}{l}\text { Planned production of } \\
\text { independent demand }\end{array}$ & $\begin{array}{l}\text { System } \\
\text { profits }\end{array}$ & $\begin{array}{c}\text { System } \\
\text { carbon } \\
\text { emissions }\end{array}$ \\
\hline 0 & {$[82.42,167.80,210.30,305.20]$} & 709.90 & 20526.00 \\
\hline 0.008 & {$[80.78,165.45,208.69,298.40]$} & 693.62 & 20188.94 \\
\hline 0.016 & {$[79.17,163.15,207.09,291.91]$} & 677.60 & 19856.00 \\
\hline 0.024 & {$[77.58,160.89,205.51,285.72]$} & 661.84 & 19530.21 \\
\hline 0.032 & {$[76.02,158.68,203.95,279.78]$} & 646.35 & 19211.21 \\
\hline 0.04 & {$[74.48,156.51,202.42,274.09]$} & 631.11 & 18898.68 \\
\hline 0.048 & {$[72.97,154.38,200.90,268.62]$} & 616.11 & 18592.30 \\
\hline 0.056 & {$[71.47,152.30,199.41,263.36]$} & 601.36 & 18291.81 \\
\hline 0.064 & {$[70.00,150.25,197.93,258.29]$} & 586.84 & 17996.94 \\
\hline 0.072 & {$[68.56,148.24,196.47,253.40]$} & 572.56 & 17707.47 \\
\hline 0.08 & {$[67.13,146.26,195.02,248.67]$} & 558.51 & 17423.16 \\
\hline 0.088 & {$[65.72,144.32,193.60,244.10]$} & 544.68 & 17143.82 \\
\hline 0.096 & {$[64.33,142.41,192.19,239.68]$} & 531.08 & 16869.26 \\
\hline 0.104 & {$[62.97,140.53,190.80,235.39]$} & 517.69 & 16599.29 \\
\hline 0.112 & {$[61.62,138.69,189.42,231.22]$} & 504.52 & 16333.76 \\
\hline 0.12 & {$[60.28,136.87,188.06,227.18]$} & 491.55 & 16072.49 \\
\hline 0.128 & {$[58.97,135.09,186.72,223.25]$} & 478.80 & 15815.36 \\
\hline 0.136 & {$[57.67,133.33,185.39,219.44]$} & 466.25 & 15562.20 \\
\hline 0.144 & {$[56.39,131.60,184.07,215.72]$} & 453.90 & 15312.90 \\
\hline 0.152 & {$[55.13,129.90,182.77,212.10]$} & 441.75 & 15067.33 \\
\hline 0.16 & {$[53.88,128.22,181.48,208.57]$} & 429.79 & 14825.37 \\
\hline 0.168 & {$[52.65,126.56,180.21,205.13]$} & 418.03 & 14586.91 \\
\hline 0.176 & {$[51.43,124.93,178.95,201.77]$} & 406.45 & 14351.85 \\
\hline 0.184 & {$[50.23,123.33,177.71,198.49]$} & 395.06 & 14120.07 \\
\hline 0.192 & {$[49.04,121.75,176.47,195.28]$} & 383.86 & 13891.49 \\
\hline 0.2 & {$[47.86,120.19,175.25,192.15]$} & 372.83 & 13666.01 \\
\hline 0.208 & {$[46.70,118.65,174.04,189.09]$} & 361.99 & 13443.55 \\
\hline 0.216 & {$[45.55,117.13,172.85,186.09]$} & 351.32 & 13224.02 \\
\hline 0.224 & {$[44.42,115.63,171.66,183.16]$} & 340.83 & 13007.34 \\
\hline 0.232 & {$[43.30,114.15,170.49,180.28]$} & 330.51 & 12793.43 \\
\hline 0.24 & {$[42.19,112.70,169.33,177.47]$} & 320.36 & 12582.23 \\
\hline 0.248 & {$[41.09,111.26,168.18,174.71]$} & 310.38 & 12373.66 \\
\hline 0.256 & {$[40.01,109.84,167.04,172.00]$} & 300.56 & 12167.65 \\
\hline 0.264 & {$[38.94,108.43,165.92,169.35]$} & 290.91 & 11964.15 \\
\hline 0.272 & {$[37.87,107.05,164.80,166.74]$} & 281.42 & 11763.08 \\
\hline 0.28 & {$[36.82,105.68,163.69,164.19]$} & 272.09 & 11564.39 \\
\hline 0.288 & {$[35.78,104.33,162.59,161.68]$} & 262.92 & 11368.02 \\
\hline 0.296 & {$[34.76,102.99,161.51,159.21]$} & 253.90 & 11173.91 \\
\hline 0.304 & {$[33.74,101.67,160.43,156.79]$} & 245.04 & 10982.01 \\
\hline 0.312 & {$[32.73,100.37,159.37,154.41]$} & 236.33 & 10792.28 \\
\hline 0.32 & {$[31.73,99.08,158.31,152.07]$} & 227.77 & 10604.66 \\
\hline
\end{tabular}

TABLE 3: Sensitivity analysis of production planning of independent demand and the supply chain profit to carbon tax $\omega$ of unit carbon emission.

At this point we can also get the planned production of independent demand and the supply chain profit under different carbon tax. The results are shown in Table 3. 
The Effect of Imposing Carbon Tax Per Unit Carbon Emission on Production Planning for Independent Demand. Figure 6 shows that, with the gradual increase of carbon tax of per unit carbon emissions, planned production of independent demand is decreased approximately linearly. And under a given carbon tax, the planned production of independent demand of the company $\mathrm{A}$ is the lowest.

The Effect of Imposing Carbon Tax Per Unit Carbon Emissions on Overall Supply Chain Carbon Emission. As can be seen from Figure 7, within a certain range, the system profit and total carbon emission reduce with the increasing of carbon tax. And this phenomenon illustrates that it is indeed an efficient and not complicated mechanism to decline the system's total carbon emissions through increasing the carbon tax. From the government's perspective, the carbon tax policy is a good policy because emissions can be greatly reduced, but from the point of view of supply chain, the carbon tax reduces system profit greatly. Similar to the case of mandatory emission cap policy, this section also build a similar system of carbon emission elasticity of profit, and we compare the result with the case of mandatory emission cap policy. With other parameters remaining unchanged, we take the optimal solution under no carbon emissions limits as the reference point (in this case the carbon tax is 0 ), and we obtained the profit and carbon emissions of the supply chain in the reference point. Similarly, we obtain the carbon emission elasticity of profit under different carbon tax in Figure 8.

As can be seen from Figure 8, with the gradual increase of carbon tax rate, the carbon emission elasticity of profit increased and then decreased, which are all greater than 1. This shows that the change rate of profit is greater than the change rate of the carbon emissions. It is clear that the supply chain and the government are more difficult to accept the results. Because the profit loss in this situation can not be neglected, and unfortunately the carbon emissions reduction is not comparatively significant. In comparison, a mandatory emissions cap policy is more excellent because regardless of carbon emissions austerity policies imposed on which company, the carbon emission elasticity of profit is less than one which is an optimum result for the government and supply chain. Therefore, for the supply chain we studied, the carbon tax policy is not prior to mandatory emission cap policy to be used in practice.

\section{Conclusion}

In this paper, we focus on how to get the optimal production planning confronting various carbon emission regulations for a complex supply chain comprising nodes firms with coupled internal dependent demand flows and random market demands. We solve the joint production optimization problem of the supply chain under mandatory emission cap and emission tax, respectively, and uncover the impact of these regulatory policies on the profit and total emission of the supply chain. We compare the optimal production quantities, profits, and overall emissions arising, respectively, from three scenarios, that is, no emission policy, mandatory emission cap, and emission tax. One of contributions of this study is

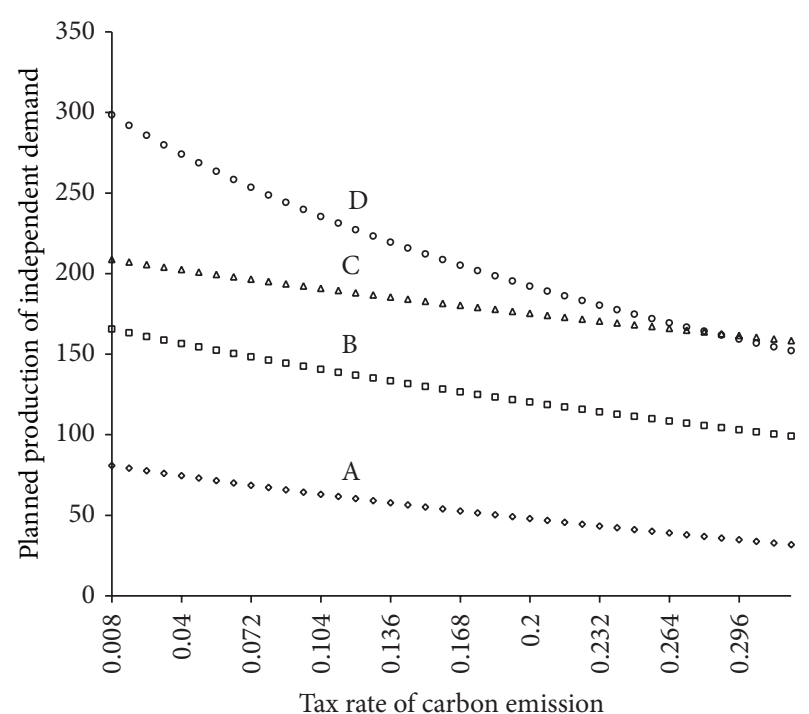

FIGURE 6: Effect of carbon tax of per unit carbon emissions on planned production of independent demand.

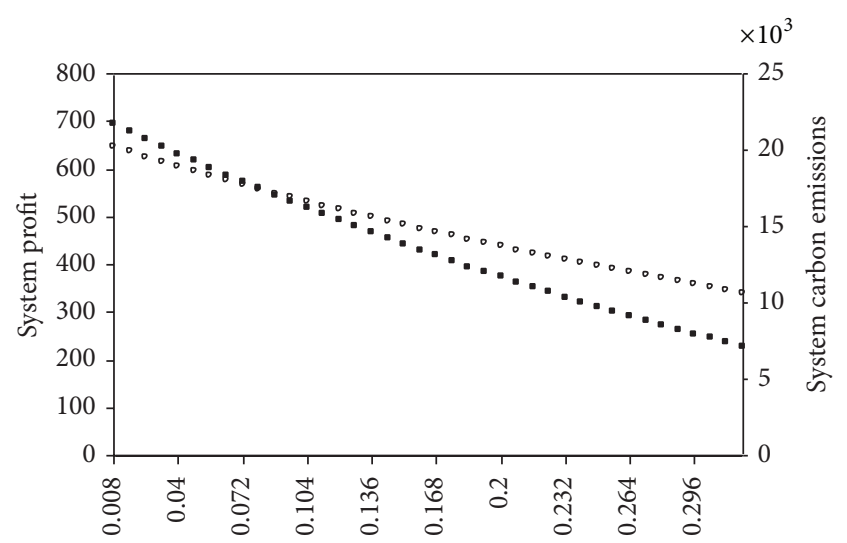

Tax rate of carbon emission

- System profit

- System carbon emissions

FIGURE 7: Effect of carbon tax of per unit carbon emissions on supply chain total carbon emission.

that we introduce the "carbon emission elasticity of profit (CEEP)" index to evaluate the influence of carbon emission regulatory policies on profit and total emissions of a supply chain and her node firms. Taking advantage of the CEEP index, we find that under the mandatory emission cap policy if we only decrease mandatory emission cap of the assembly company by a certain proportion, the CEEP index is lowest compared with situations where we instead decrease the cap of other node firms by same scale. Meanwhile, the value of the index is between 0 and 1, namely, nonelastic, which implies we can reach the emission control target at a relatively low price of profit loss. That is obviously acceptable both for the supply chain and public administration. As for the scenario of carbon tax policy, we find that the CEEP is elastic, which in turn indicates it should not be prior to mandatory 


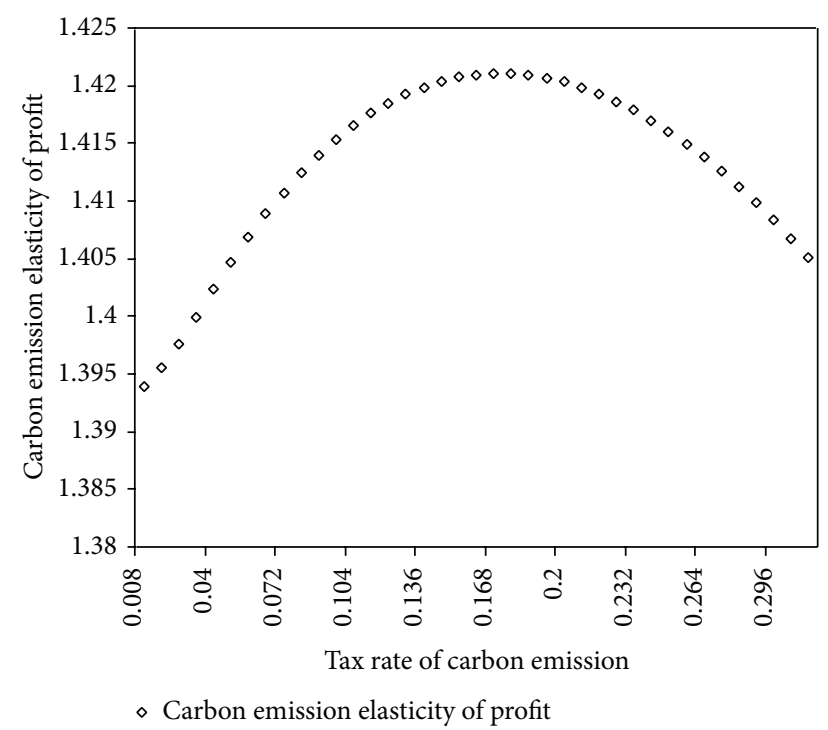

Figure 8: Carbon emission elasticity of profit under different carbon tax.

emission cap policy to be adopted and preferred by industry and government.

There may be some extension in the future. For example, one can consider the multiple-horizon production planning problem in the same supply chain structure under lowcarbon constraints. One can also add the pricing decision into the consideration.

\section{Appendix}

Proof. The objective function of the supply chain

$$
\begin{aligned}
\max _{q_{i}^{L} \geq 0} \prod=E(\pi)=\sum_{i=1}^{n}\left\{\begin{array}{l}
\left(p_{i}+s_{i}\right) \cdot q_{i}^{L} \\
\\
\quad-\left(p_{i}+h_{i}+s_{i}\right) \int_{0}^{q_{i}^{L}} F\left(X_{i}\right) d X_{i}
\end{array}\right. \\
\left.\quad-K_{i}-s_{i} \mu_{i}-v_{i} \cdot \sum_{j=1}^{n} d_{i j} q_{j}^{L}\right\}
\end{aligned}
$$

can be written as

$$
\begin{gathered}
\min _{q_{i}^{L} \geq 0, i \in N} J\left(Q_{L}\right)=\sum_{i=1}^{n}\left\{-\left(p_{i}+s_{i}\right) \cdot q_{i}^{L}+\left(p_{i}+h_{i}+s_{i}\right)\right. \\
\cdot \int_{0}^{q_{i}^{L}} F_{i}(x) d x+s_{i} \mu_{i} \\
\left.+K_{i}+v_{i} \cdot \sum_{j=1}^{n} d_{i j} q_{j}^{L}\right\}
\end{gathered}
$$

In order to prove that the target function $\Pi$ is the concave function, this needs to prove that function $J\left(Q_{L}\right)$ is convex function.

Construct a function $\phi(x)=\int_{0}^{x} F(t) d t$, its second derivative $\phi^{\prime \prime}(x)=f(x)>0$; thus $\phi(x)$ is a convex function, to its domain for all $x_{1}, x_{2}>0$, we have $\phi\left(\lambda x_{1}+\bar{\lambda} x_{2}\right) \leq \lambda \phi\left(x_{1}\right)+$ $\bar{\lambda} \phi\left(x_{2}\right)$, so $\int_{0}^{\lambda x_{1}+\bar{\lambda} x_{2}} F(t) d t \leq \lambda \int_{0}^{x_{1}} F(t) d t+\bar{\lambda} \int_{0}^{x_{2}} F(t) d t$, where $0 \leq \lambda \leq 1, \bar{\lambda}=1-\lambda$ 。 So we get $\int_{0}^{\lambda q_{1}^{i}+\bar{\lambda} q_{2}^{i}} F_{i}(x) d x \leq$ $\lambda \int_{0}^{q_{1}^{i}} F_{i}(x) d x+\bar{\lambda} \int_{0}^{q_{2}^{i}} F_{i}(x) d x_{\circ}$.

Thus

$$
\begin{aligned}
& J\left(\lambda Q_{1}^{L}+\bar{\lambda} Q_{2}^{L}\right)-\left[\lambda J\left(Q_{1}^{L}\right)+\bar{\lambda} J\left(Q_{2}^{L}\right)\right] \\
& =\sum_{i=1}^{n}\left\{-\left(p_{i}+s_{i}\right) \cdot\left(\lambda q_{1}^{i}+\bar{\lambda} q_{2}^{i}\right)+\left(p_{i}+h_{i}+s_{i}\right)\right. \\
& \cdot \int_{0}^{\left(\lambda q_{1}^{i}+\bar{\lambda} q_{2}^{i}\right)} F_{i}(x) d x+s_{i} \mu_{i}+K_{i} \\
& \left.+v_{i} \cdot \sum_{j=1}^{n} d_{i j}\left(\lambda q_{1}^{j}+\bar{\lambda} q_{2}^{j}\right)\right\} \\
& -\lambda \sum_{i=1}^{n}\left\{-\left(p_{i}+s_{i}\right) \cdot q_{1}^{i}+\left(p_{i}+h_{i}+s_{i}\right)\right. \\
& \left.\cdot \int_{0}^{q_{1}^{i}} F_{i}(x) d x+s_{i} \mu_{i}+K_{i}+v_{i} \cdot \sum_{j=1}^{n} d_{i j} q_{1}^{j}\right\} \\
& -\bar{\lambda} \sum_{i=1}^{n}\left\{-\left(p_{i}+s_{i}\right) \cdot q_{2}^{i}+\left(p_{i}+h_{i}+s_{i}\right)\right. \\
& \left.\cdot \int_{0}^{q_{2}^{i}} F_{i}(x) d x+s_{i} \mu_{i}+K_{i}+v_{i} \cdot \sum_{j=1}^{n} d_{i j} q_{2}^{j}\right\} \\
& =\sum_{i=1}^{n}\left(p_{i}+h_{i}+s_{i}\right)\left[\int_{0}^{\lambda q_{1}^{i}+\bar{\lambda} q_{2}^{i}} F_{i}(x) d x-\lambda \int_{0}^{q_{1}^{i}} F_{i}(x) d x\right. \\
& \left.-\bar{\lambda} \int_{0}^{q_{2}^{i}} F_{i}(x) d x\right] .
\end{aligned}
$$

In this formula, $\left(p_{i}+h_{i}+s_{i}\right)>0$, and we can calculate from the formula and get $\int_{0}^{\lambda q_{1}^{i}+\bar{\lambda} q_{2}^{i}} F_{i}(x) d x-\lambda \int_{0}^{q_{1}^{i}} F_{i}(x) d x-$ $\bar{\lambda} \int_{0}^{q_{2}^{i}} F_{i}(x) d x \leq 0$. So $J\left(\lambda Q_{1}^{L}+\bar{\lambda} Q_{2}^{L}\right)-\left[\lambda J\left(Q_{1}^{L}\right)+\bar{\lambda} J\left(Q_{2}^{L}\right)\right]<0$; that means $J\left(Q_{L}\right)$ is a convex function. Therefore $\prod$ is a concave function; then there is a global optimum point. 


\section{Conflict of Interests}

The authors declare that there is no conflict of interests regarding the publication of this paper.

\section{Acknowledgments}

The authors would like to express their sincere thanks to the anonymous referees and editors for their time and patience devoted to the review of this paper. This work is partially supported by NSFC Grant (no. 71202086).

\section{References}

[1] L. J. Xia, D. Zhao, and B. Yuan, "Carbon efficient supply chain management: literature review with extensions," Applied Mechanics and Materials, vol. 291-294, pp. 1407-1412, 2013.

[2] J. Song and M. Leng, "Analysis of the single-period problem under carbon emissions policies," in Handbook of Newsvendor Problems, vol. 176 of International Series in Operations Research and Management Science, pp. 297-313, Springer, New York, NY, USA, 2012.

[3] Congress of the United States, Policy options for reducing Co2 emissions: a CBO study. This study was provided by the Congressional Budget Office (CBO), 2008.

[4] S. Benjaafar, Y. Li, and M. Daskin, "Carbon footprint and the management of supply chains: Insights from simple models," IEEE Transactions on Automation Science and Engineering, vol. 10, no. 1, pp. 99-116, 2013.

[5] S. Dhakal, "Urban energy use and carbon emissions from cities in China and policy implications," Energy Policy, vol. 37, no. 11, pp. 4208-4219, 2009.

[6] D. Holtz-Eakin and T. M. Selden, "Stoking the fires? $\mathrm{CO}_{2}$ emissions and economic growth," Journal of Public Economics, vol. 57, no. 1, pp. 85-101, 1995.

[7] X. Zhang and X. Cheng, "Energy consumption, carbon emissions, and economic growth in China," Ecological Economics, vol. 68, no. 10, pp. 2706-2712, 2009.

[8] X. Leng, Research on the relationship between carbon emission and China's economics [Thesis], Fudan University, 2012.

[9] Q. Zhu, X. Z. Peng, Z. M. Lu, and K. Y. Wu, "Factor decomposition and empirical analysis of changes in carbon emissions in China's energy consumption," Resources Science, vol. 31, no. 12, pp. 2072-2079, 2009.

[10] J. W. Sun and Z. G. Chen, "Research on China's carbon emissions footprint based on input-output analysis," China Population Resources and Environment, vol. 20, no. 5, pp. 28-34, 2010.

[11] M. L. Cropper and E. Oates, "Environmental economics: a survey," Journal of Economic Literature, vol. 30, no. 2, pp. 675740, 1992.

[12] C. Hepburn, "Regulation by prices, quantities, or both: a review of instrument choice," Oxford Review of Economic Policy, vol. 22, no. 2, pp. 226-247, 2006.

[13] M. Webster, I. S. Wing, and L. Jakobovits, "Second-best instruments for near-term climate policy: intensity targets vs. the safety valve," Journal of Environmental Economics and Management, vol. 59, no. 3, pp. 250-259, 2010.

[14] B. Bureau, "Distributional effects of a carbon tax on car fuels in France," Energy Economics, vol. 33, no. 1, pp. 121-130, 2011.
[15] S. Benjaafar, Y. Li, M. Daskin, L. Qi, and S. Kennedy, The Carbon Footprint of UHT Milk, University of Minnesota, Minneapolis, MN, USA, 2010.

[16] D. Pan, Optimal decision of the companies production under lowcarbon economy, Yanshan University, 2012.

[17] B. S. Kang and J. S. Yoon, "Sheet forming apparatus with flexible rollers," PCT Patent pending, 2013.

[18] X. Chen, S. Benjaafar, and A. Elomri, "The carbon-constrained EOQ," Operations Research Letters, vol. 41, no. 2, pp. 172-179, 2013.

[19] G. P. Cachon, "Carbon footprint and the management of supply chains," in Proceedings of the INFORMS Annual Meeting, San Diego, Calif, USA, 2009.

[20] A. Ramudhin, A. Chaabane, M. Kharoune, and M. Paquet, "Carbon market sensitive green supply chain network design," in Proceedings of the IEEE International Conference on Industrial Engineering and Engineering Management (IEEM '08), pp. 10931097, December 2008.

[21] T. Abdallah, A. Diabat, and D. Simchi-Levi, "A carbon sensitive supply chain network problem with green procurement," in Proceedings of the 40th International Conference on Computers and Industrial Engineering (CIE40 '10), Awaji, Japan, July 2010.

[22] A. Ramudhin, A. Chaabane, M. Kharoune, and M. Paquet, "Design of sustainable supply chains under the emission trading scheme," International Journal of Production Economics, vol. 135, no. 1, pp. 37-49, 2012.

[23] D. Zhao and J. Lv, "Carbon-efficient strategy for integrated supply chain considering carbon emission rights and trading," Industrial Engineering and Management, vol. 17, no. 5, pp. 65-71, 2012.

[24] L. He, Supply network optimization based on coordination mechanism design considering diverse chain structures [Dissertation], Tianjin University, 2010.

[25] F. R. Jacobs and R. B. Chase, Operations Management, Mechanical Industry Press, Beijing, China, 2011.

[26] L. He, H. Lu, and D. Zhao, "Quick response based joint dynamic production optimization for a complicated supply chain under internally interwined demand dependence," Journal of Systems Science and Mathematical Sciences, vol. 34, no. 1, pp. 20-42, 2014.

[27] L. He, "Optimal joint output analysis of complex supply networks with stochastic demands," Working Paper, Tianjin University, 2012. 


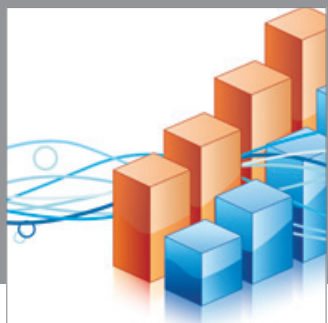

Advances in

Operations Research

mansans

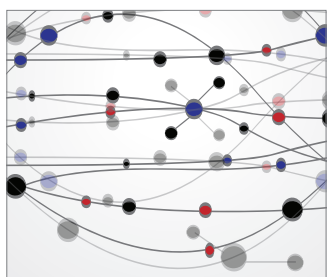

The Scientific World Journal
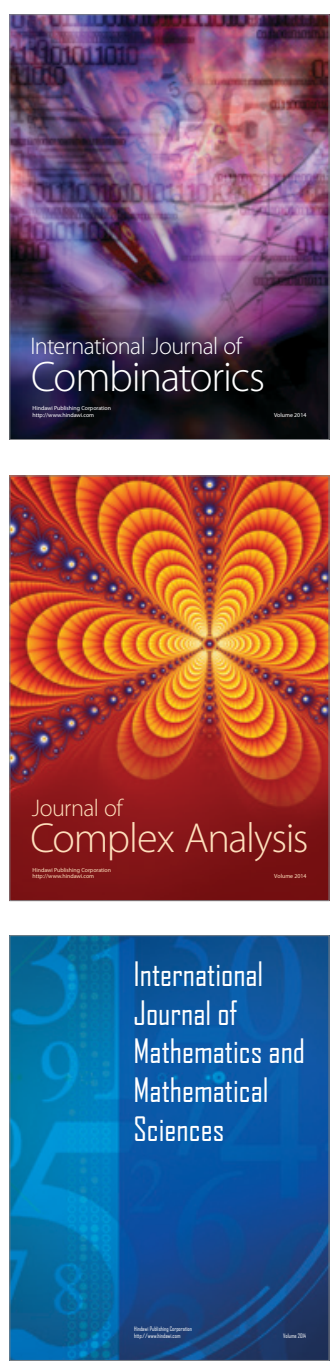
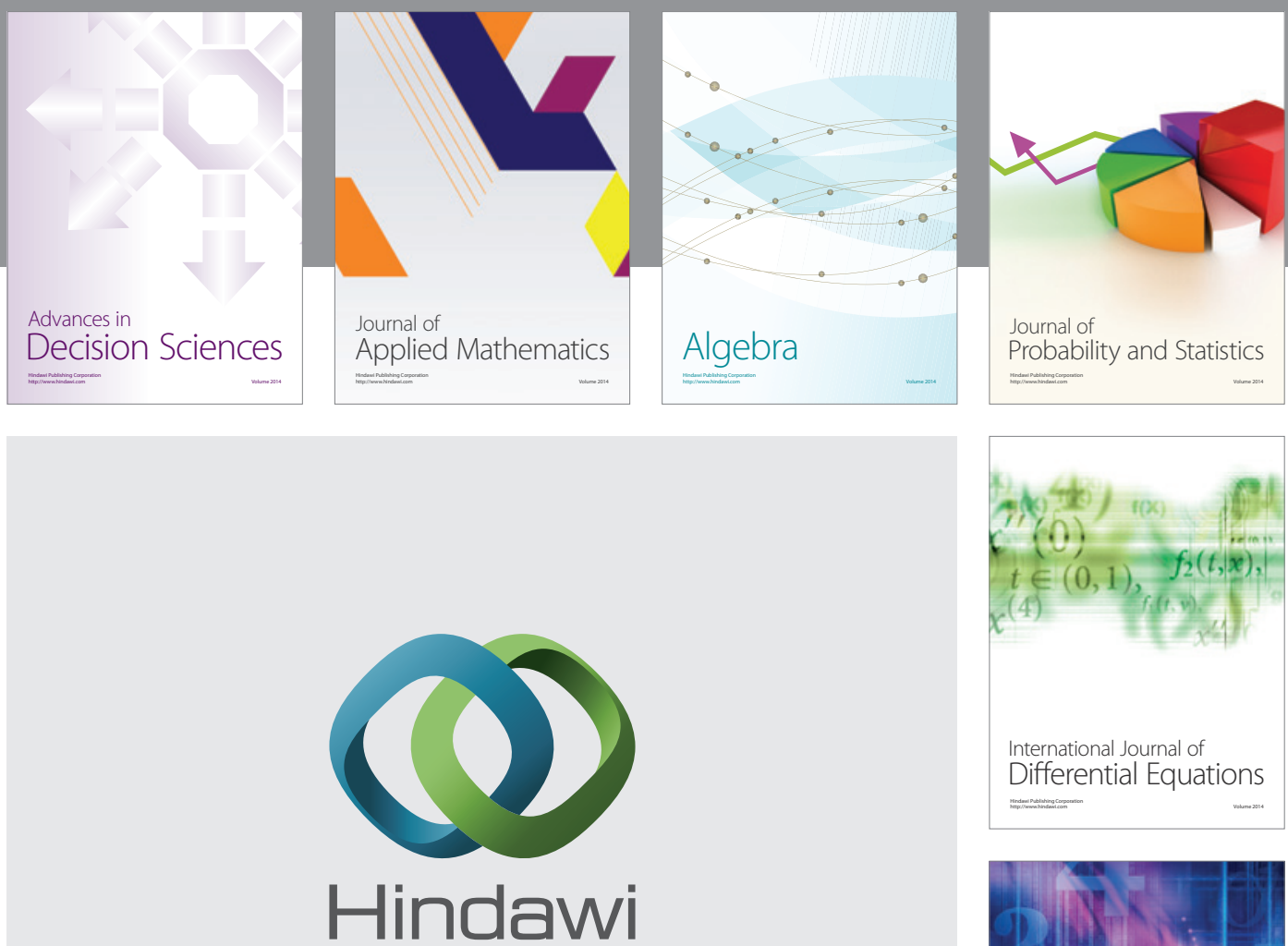

Submit your manuscripts at http://www.hindawi.com
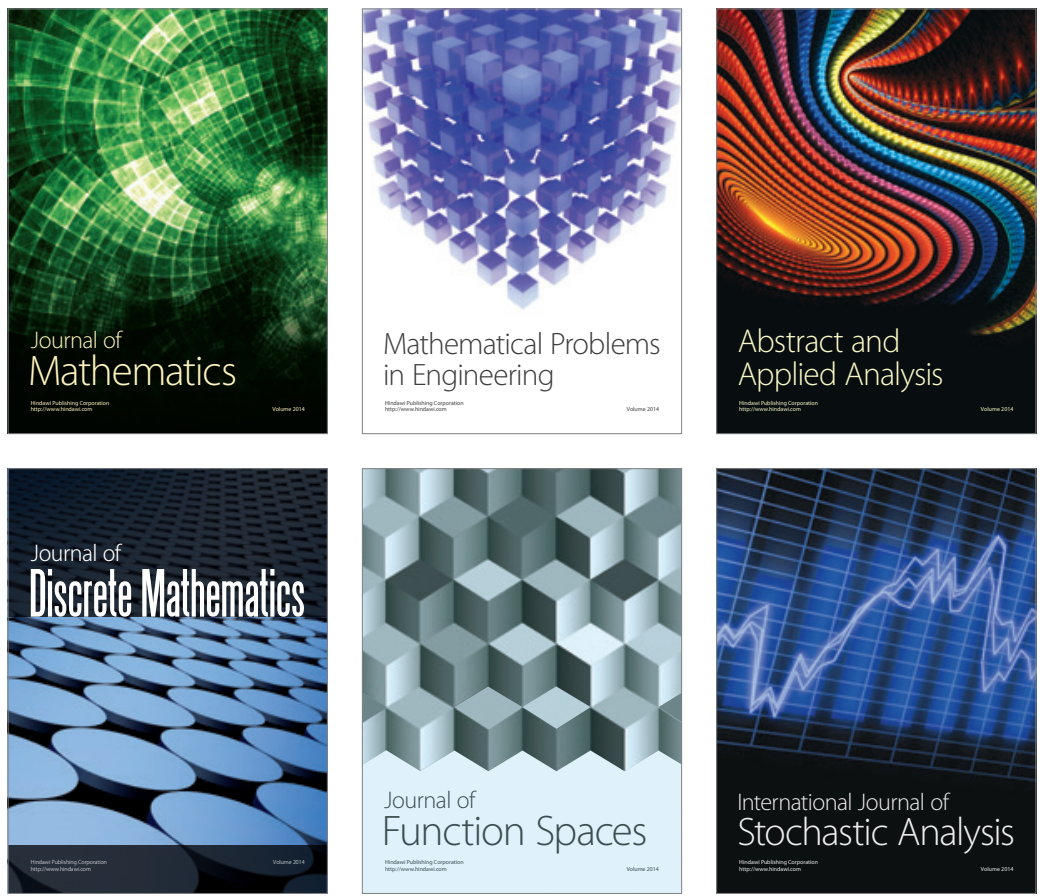

Journal of

Function Spaces

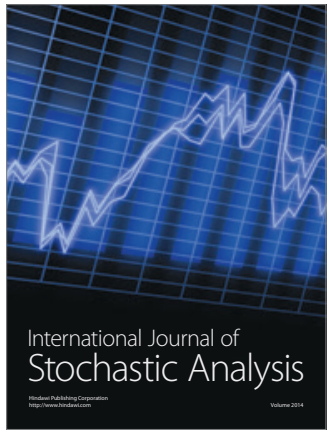

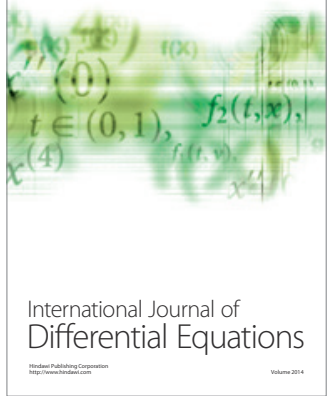
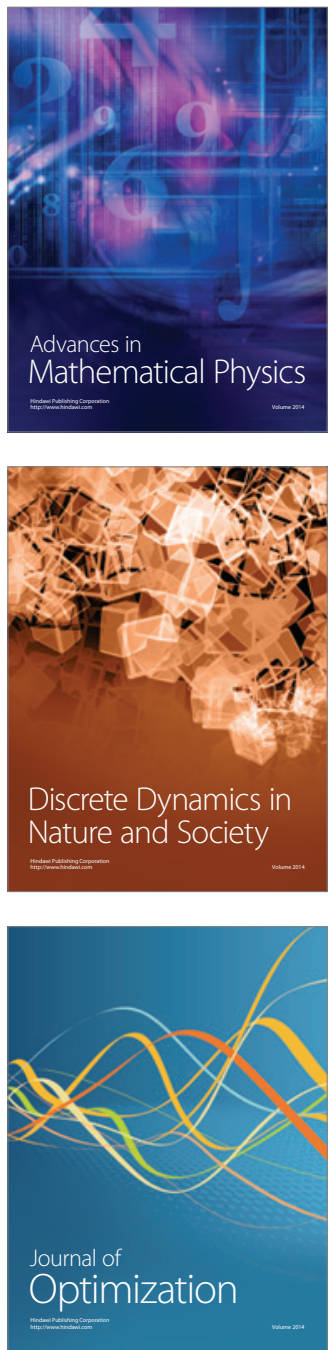